\title{
ЦЕННОСТИ ПОЖИЛЫХ И ПОЛИТИЧЕСКИЕ ПОСЛЕДСТВИЯ ГЛОБАЛЬНОГО СТАРЕНИЯ НАСЕЛЕНИЯ
}

\author{
КИРИЛЛ НОВИКОВ, ДАРЬЯ БЫКАНОВА
}

\begin{abstract}
Представленный обзор посвящен нескольким проблемам в политической и социальной геронтологии, а также экономическим проблемам, вызванным глобальным старением населения. В тексте анализируются подходы различных авторов к определению старости и ее психологических, поведенческих и социальных аспектов. Рассматриваются вопросы активного старения, социального конструирования стереотипов в отношении пожильх и эйджизма. В документах Всемирной организации здравоохранения понятие «активное старение» определяется как «прочесс оптимизаџии возможностей для здоровья, участия и безопасности в целях повышения качества жизни стареюших людей» [World Health Organization 2002]. Описываются два основных подхода к изучению экономических последствий старения населения: в первом случае изучаются тренды макроуровня, возникающие при изменении соотношения трудоспособного и нетрудоспособного населения, во втором случае в центре внимания оказываются особенности экономического поведения пожильх, включая их поведение на рынке труда, на финансовом и потребительском рынках. Приводятся данные об участии международных структур в исследовании экономических вопросов, связанном с мировыми демографическим изменениями. Основное внимание в обзоре уделяется исследованиям, посвященным политическим последствиям возрастания доли пожильх в современном обществе, в особенности в развитых демократиях. Рассматриваются подходы $\kappa$ описанию политической активности пожильх, включающей участие в выборах, в акциях протеста $u$ др. Значительное внимание уделяется проблеме ценностей пожильх, в особенности их предполагаемому консерватизму. Часть авторов утверждает, что иеенности пожильх связаны с возрастными изменениями организма и, таким образом, имеют возрастной характер. Другие авторы, и таких сейчас большинство, полагают, что иенности вырабатываются в процессе социализации «политических поколений» и мало меняются к старости. Также рассматривается вопрос о том, не становятся ли пожилье отдельной группой, имеющей свои интересы и способной навязать обществу свою особую повестку дня. Наконеи, приводятся результать исследований, посвященных когнитивным особенностям пожильх, влияющим на принятие ими политических и иных решений.
\end{abstract}

Ключевые слова: старение населения, политика, консерватизм, ценности, эйджизм.

\section{СТАРЕНИЕ НАСЕЛЕНИЯ И ПОЛИТИКА}

Решения, которые человек принимает на протяжении своей жизни, обычно так или иначе связаны с ценностями, которые он разделяет. Это относится и к политическим решениям, касающимся электорального поведения, участия в массовых мероприятиях или действий на ответственном посту. Система ценностей может включать в себя представления о морали, о социальной справедливости, о желательной форме правления и надлежащих отношениях между государством и его гражданами и др., т.е. может оказывать воздействие на все сферы общественной жизни. При этом члены одного общества не всегда разделяют одни и те же ценности. В частности, за молодыми закрепилась репутация бунтарей, а за пожилыми консерваторов. Такое разделение может иметь серьезные последствия для политического развития общества, особенно если меняется соотношение численности возрастных групп, что как раз и происходит в настоящее время.

КИРИЛЛ ЕвГЕНЬЕВИч НовИков (kenovikov@yandex.ru), ИНСТИТУТ ЭКОНОМИЧЕСКОЙ ПОЛИТИКИ ИМ. Е.Т. ГАЙДАРА И ИНСТИТУТ СОЦИОЛОГИИ РАН, РОССИЯ.

ДАРЬЯ АЛЕКСЕЕВНА БЫКАНОВА (bykanova-da@ranepa.ru), РОССИЙСКАЯ АКАДЕМИЯ НАРОДНОГО ХОЗЯЙСТВА И ГОСУДАРСТВЕННОЙ СЛУЖБЫ ПРИ ПРЕЗИДЕНТЕ РОССИЙСКОЙ ФЕДЕРАЦИИ, РОССИЯ. 
Население планеты стареет, и Россия следует общему тренду: доля пожилых в населении нашей страны растет. В связи с этим представляется важным ответить на вопросы: действительно ли пожилые обладают особым набором ценностей и чем обусловлены отличия этих ценностей? Эти вопросы уже давно занимают исследователей во всем мире, поэтому создание обзора литературы, посвященной проблеме ценностей пожилых, представляется полезным и своевременным. Разработка проблемы ценностей пожилых может способствовать выработке наиболее эффективных политических решений на федеральном, региональном и муниципальном уровнях Российской Федерации, что, как представляется, может снизить социальную напряженность и способствовать развитию человеческого капитала в стране. Вопросы политических последствий демографического старения изначально выводились из осознания возможных экономических последствий увеличения доли пожилого нетрудоспособного населения. Первые опасения по поводу замедления экономического развития общества с увеличением доли пожилых были высказаны в послевоенные годы. В 1949 г. британская Королевская комиссия по народонаселению опубликовала доклад, в котором высказывалось расхожее мнение о том, что пожилые, несмотря на опыт и жизненную мудрость, менее активны, с трудом поддаются обучению и с трудом воспринимают новое. Комиссия выразила опасения по поводу возможных изменений в возрастном составе общества: «Представляется возможным, что общество, в котором доля молодых людей сокращается, станет угрожающе непрогрессивным, начав отставать от других обществ не только по технической эффективности и экономическим благам, но и в области интеллектуальных и культурных достижений» [Report... 1949].

Старение населения давно стало восприниматься как вызов для государства, которому предстояло выработать подходы в рамках публичной политики для решения возникающих проблем. В 1970-е годы возникла «политэкономия старости», или «экономическая геронтология», бравшаяся за теоретическое описание новой экономической ситуации и соответствующих ей политических подходов. Политэкономия ставила вопрос о том, как государство и его институты управляют своими ресурсами в интересах пожилых. Позднее эти исследования трансформировались в изучение экономических последствий старения населения, в частности, Минсер одним из первых заговорил об уменьшении человеческого капитала при старении населения [Mincer 1974]. В настоящее время прогнозируется, что к середине века в ряде развитых стран, таких как Германия, Япония и США, доля жителей от 65 лет и старше должна значительно увеличиться, что приведет к сокращению налоговых поступлений, в то время как пенсионеры и получатели различных пособий составят значительную часть электората [Sanderson, Scherbov 2007].

Практически одновременно с экономической геронтологией возникла политическая геронтология, ставившая целью изучить политические аспекты старения населения. Политическая геронтология изначально структурировалась как междисциплинарная область знания, в которой использовались данные и методы, заимствованные у демографии, социальной психологии и политического анализа. Основным постулатом политических геронтологов стало убеждение в том, что политическое влияние пожилых будет возрастать по мере увеличения их доли в составе населения. Среди ранних работ следует отметить 
труды Глена [Glenn, Grimes 1968; Glenn 1969; Glenn, Hefner 1972], Катлера [Cutler 1970; 1977], Бинстока [Binstock 1972; 1974], Кэмбелла [Campbell 1971].

Политическая геронтология так и не стала общепризнанной дисциплиной, хотя в современном учебнике по геронтологии Комп и Аарстен ей посвящен целый раздел [Котр, Aarsten 2013]. Внутри проблемного поля политической геронтологии обозначились несколько вопросов, которые обычно решаются в рамках других, давно устоявшихся дисциплин, что сделало формальное обособление этой науки неактуальным.

Прежде всего, стоит вопрос о теоретическом осмыслении процесса старения в его социальном и политическом аспектах. Во-вторых - вопрос об экономических последствиях сдвигов в демографической структуре населения. Наконец, стоит вопрос о политических последствиях старения населения, который можно разбить на два вопроса.

Первый вопрос: как правительства и политические институты реагируют или должны реагировать на старение населения?

Второй вопрос: какое влияние на политический процесс могут оказать пожилые?

Этот вопрос может быть разделен на несколько подвопросов:

А. Каковы возможные последствия старения политического руководства страны?

В. Осознают ли пожилые себя в качестве особой группы интересов?

C. Обладают ли пожилые особой системой ценностей?

D. Влияет ли возраст на когнитивные способности, задействованные при принятии политических решений?

\section{ОСМЫСЛЕНИЕ ПРОЦЕССА СТАРЕНИЯ}

В послевоенные годы возникло междисциплинарное поле исследований, известное как социальная геронтология. Внимание к людям старшего возраста усилилось в связи со становлением социального государства, для которого помощь пожилым становилось одним из приоритетов. В США наблюдался активный рост интереса к этой тематике между 1950 и 1975 гг., причем первопроходцами были медики и психологи, такие как Кулен [Kuhlen 1956].

Социологи-функционалисты выдвинули теорию «отсоединения» (disengagement), согласно которой старость характеризуется утратой социальных функций и связей. В частности, Камминг и Генри говорили, что социальная роль пожилых - это «роль без роли» (roleless role) [Cumming, Henry 1961]. Они полагали, что постепенное отсоединение пожилого от социальных ролей полезно для общества и для него самого. Бромлей объяснял отсоединение сокращением физических и психических возможностей пожилых [Bromley 1966].

В то же время возникла теория активности, которая настаивала, что утрата социальных ролей в старости вовсе не обязательна и даже нежелательна. В частности, Хэвигхерст и Альбрехт полагали, что старость должна быть временем активной и творческой жизни [Havighurst, Albrecht 1953]. Эта система взглядов имела гуманистический 
заряд, хотя игнорировала вопросы неравенства, конфликта между возрастными группами, т.е. фактически выносила политические проблемы за скобки.

Важным этапом развития философии старения стали работы Эриксона, предложившего теорию жизненных циклов. Согласно Эриксону, старость представляет собой важный период в жизни человека, когда происходит окончательное становление его личности путем интеграции и осмысления жизненного опыта [Erikson 1982; Erikson et al. 1986].

Проблема старости была политизирована геронтологами, прежде всего Робертом Батлером, который в 1969 г. ввел термин «эйджизм», обозначив им дискриминацию в отношении пожилых, подобную расизму и сексизму [Butler 1969]. К такой дискриминации вели, в частности, представления о том, что пожилые должны «отключаться» от своих социальных ролей. На волне борьбы за гражданские права эйджизм стал восприниматься как дополнительный фактор угнетения меньшинств. В частности, Джексон исследовала ситуации, когда эйджизм усугублял положение пожилых афроамериканок наряду с расовой и гендерной дискриминацией [Jackson 1974]. В то же время Нойгартен выражала оптимизм по поводу возникновения группы «молодых стариков» в возрасте 55-75 лет, которые, по ее мнению, должны были трансформировать американское общество, избавив его от пережитков эйджизма [Neugarten 1974].

Увлечение постмодернистскими теориями привело к тому, что старость все чаще стали рассматривать как социокультурный конструкт, включающий серию стереотипов и устойчивых репрезентаций. Роль стереотипов подчеркивали Брюер, Далл и Луи, показавшие, что молодые люди с трудом усваивают информацию о пожилых, если эта информация расходится с их представлениями о том, какими должны быть старики [Brewer et al. 1981]. Проблему стереотипов во взаимном восприятии поколений активно разрабатывает Хаммерт [Hummert 1990]. Физерстоун и Верник описали процесс конструирования таких стереотипов через визуальные образы культуры [Featherstone, Wernick 1995]. Методология конструктивизма позволила ряду авторов говорить об искусственности и устарелости наших представлений о старости [Powell 2006; Baars et al. 2006].

В настоящее время движение за права пожилых успешно развивается, в том числе в научных публикациях. Из современных авторов следует выделить работы Т.Д. Нельсона [Nelson 2004; 2005; 2016] и Э. Палмора [Palmore 1999; 2004; 2005; 2009; 2011]. В России проблема стигматизации и социального исключения пожилых рассматривалась в трудах Писарева [2004], Красновой [2005], Кравчука и Шкариной [2007], Смолькина [2007, 2010, 2015], Смирновой [2008] и ряда других авторов.

В последнее время проблематика эйджизма все чаще рассматривается через призму феминизма. Браун и Ролингер показали, что активное участие в женском движении позволяет его пожилым участницам преодолевать стереотипы старения [Brown, Rohlinger 2016]. В то же время Новикова описывает ситуацию в Польше, где за пожилыми женщинами закрепился стереотип ультраконсервативных поборниц католицизма [Novikova 2016]. Традиционные исследования дискриминации по признаку возраста также остаются актуальными [Marques et al. 2017]. 
В целом старость сегодня понимается не только как паспортный возраст или состояние здоровья, но и как социальный конструкт, отчасти навязанный стереотипами, не соответствующими современным демографическим и, главным образом, социальнопсихологическим условиям [Miller et al. 2004; Hummert et al. 1995; 2004]. Существует и другой подход к определению старости. У. Сандерсон и С.Я. Щербов предлагают понимать старость как уровень социальной активности, связанный с состоянием здоровья, измеряемый на основе объективных показателей [Sanderson, Scherbov 2016a, 2016b].

В настоящее время активно обсуждаются вопросы дискриминации пожилых на рабочем месте [King, Bryant 2017; Harris et al. 2017; Drydakis et al. 2017], а также в других сферах общественной жизни.

Серьезно рассматриваются и другие социальные последствия старения, никак не связанные с эйджизмом. Хейджстед и Уленберг разбирают вопрос о том, ведет ли изменение структуры современной семьи к исключению пожилых из жизни общества [Hagestad, Uhlenberg 2006]. Кон проводит сравнение социальных последствий старения населения в развитых и развивающихся странах [Cohn 2016], Саманта сравнивает социальные и культурные аспекты старения в Европе, Японии, Китае, Израиле, Нигерии и Ливане [Samanta 2017]. Исследования повседневной жизни пожилых людей проводятся также на муниципальном уровне, как, например, в недавней работе Веро и Джардино, посвященной пожилым жителям одного из районов Турина [Vero, Giardino 2017]. Разным социальным аспектам старения посвящены работы Комп и ее соавторов [Komp, Van Tilburg 2010; Komp et al. 2010; Komp 2011; 2013; Komp, Marier 2015]. В этих работах освещается широкий круг вопросов, включая психологию старения, государственную политику поддержки пожилых и возможные последствия такой поддержки для экономики.

\section{ЭКОНОМИЧЕСКИЕ ПОСЛЕДСТВИЯ СТАРЕНИЯ НАСЕЛЕНИЯ}

Рост доли пожилых в населении западных стран заставлял ставить вопрос об экономическом поведении пенсионеров. В частности, Морин и Суарес [Morin, Suarez 1983], Макиниш, Рамасвами и Сривастава [McInish et al. 1993], Бакши и Чен [Bakshi, Chen 1994] и другие авторы показали, что с возрастом инвесторы становятся более склонны избегать рискованных капиталовложений. Появились исследования, описывающие поведение пожилых на потребительском рынке и на рынке труда. В частности, Альдерс показал, что пенсионеры часто отказываются от работы, даже если могут работать, в случае если пенсионное обеспечение позволяет им жить в свое удовольствие [Alders 1999]. Таким образом, исследования подтверждали опасения тех, кто предвидел негативные последствия роста доли пожилых. Неоднократно поднимался вопрос о повышении пенсионных расходов и демографической нагрузки пожилыми на работающее население.

Как отмечает Кул [Cool 2012], стратегия борьбы с возможными последствиями старения была впервые представлена в докладе Всемирного банка от 1994 г. под названием «Предотвращение кризиса старения» [World Bank... 1994]. В докладе предлагалось бороться с кризисом неолиберальными мерами, т.е. предполагалось снять часть нагрузки с государственных бюджетов, переложив ее на коммерческие финансовые структуры. 
С начала 2000-х годов Международный валютный фонд опубликовал несколько исследований, посвященных старению населения и его последствиям [International Monetary... 2000, 2002, 2005, 2008]. В докладе ЦРУ за 2001 г. «Долгосрочные глобальные демографические тренды: меняя геополитический ландшафт» [CIA 2001] повторялись предостережения Королевской комиссии: «Исторически самые богатые и развитые страны были растущими гигантами, распространявшими свои капиталы, силу, нравы и благотворительность по всему миру. Уже четверть века, как эти страны, находясь под угрозой демографического вызова, рискуют превратиться в финансово стесненных нейтралов, отчаянно маневрирующих, дабы избежать международной вовлеченности. Электорат, в котором доминируют пожилые, возможно, будет избегать риска и решительных столкновений за границей, предпочитая идти на подходящие случаю (ad hoc) соглашения». В докладе также содержалось предположение, что стареющая Япония столкнется с нехваткой молодых инноваторов, что затормозит ее технологический прогресс. Ряд исследователей высказывают мнение, что старение населения в развитых странах может привести к изменению геополитического баланса в мире. В частности, Джексон и Хоув считают, что к середине XXI века США и их традиционным союзникам будет все труднее обеспечивать глобальную систему безопасности [Jackson, Howe 2008].

Оптимистическая точка зрения на возможности использования трудового потенциала пожилых была высказана в Мадридском международном плане действий по проблемам старения 2002 г. ${ }^{1}$ Вместе с тем с начала века мнение о том, что процесс старения потребует изменений политики правительств в сторону увеличения социальных расходов на пожилых, практически не подвергалось сомнению. Геллер рассматривает старение населения в одном ряду с изменением климата и другими глобальными вызовами [Heller 2003]. Грант и Хуренс описывают перспективы политики стимулирования рождаемости в новых демографических условиях [Grant, Hoorens 2006], в то время как Магнус пытается дать общую картину надвигающихся перемен [Magnus 2009]. О неизбежности бюджетных проблем пишут Гонзалес-Эирас и Нипельт [Gonzalez-Eiras, Niepelt 2012a; $2012 \mathrm{~b}$ ]. Каснаускиене и Михневич [Kasnauskiene, Michnevic 2015] подтверждают на европейском материале взаимосвязь демографических показателей с ростом ВВП и констатируют, что институты социальной защиты стран ЕС могут оказаться под угрозой из-за замедления экономического роста. В то же время К. Михневич демонстрирует сильную негативную связь между долей населения в возрасте от 65 лет и уровнем потребления домохозяйств, что также не способствует экономическому росту [Michnevic 2016].

В последнее время экономические проблемы, связанные со старением населения, рассматриваются как на межстрановом, так и на региональном уровне. Так, Лисенкова, Мерет и Райт строят модель изменений на рынке труда для Шотландии [Lisenkova et al. 2012], а Касаматта и Батте пытаются предсказать проблемы, с которыми столкнутся развивающиеся страны в связи с ростом нагрузки на их пенсионные системы [Casamatta, Batté 2016]. Мау отмечает, что нынешняя российская пенсионная система является

\footnotetext{
${ }^{1}$ Мадридский международный план действий по проблемам старения 2002 года. URL: http://www.un.org/ru/documents/decl_conv/declarations/ageing_program.shtml (дата обращения: 11.09.2017).
} 
наследницей системы, сложившейся в $\mathrm{XX}$ веке, и не соответствует сегодняшней демографической ситуации. Выход ему видится в «диверсификации, индивидуализации и приватизации» пенсионной системы, что подразумевает перенос ответственности за пенсионные накопления с государства на самих граждан ${ }^{2}$.

В России вопрос об экономическом поведении пожилых остается дискуссионным. Рогозин утверждает, что российские пенсионеры лишь на словах остаются приверженцами устаревших патерналистских моделей, согласно которым пожилые должны исключить себя из общественной жизни и жить за счет государственной поддержки. На деле пожилые россияне реализуют стратегию активного старения, стараясь заниматься производительным трудом, пока позволяет здоровье. По мнению Рогозина, основным мотивом работающих пенсионеров является не борьба за экономическое выживание, а стремление сохранять включенность в социальные и профессиональные отношения [Рогозин 2012]. В то же время Смолькин отмечает, что российским пожилым сегодня не хватает навыков, таких как навыки работы с компьютером и Интернетом, которые помогли бы им интегрироваться в современном мире [Смолькин 2014]. Елютина и Болотов полагают, что большинство пенсионеров находится в режиме жесткой экономии и живет от пенсии до пенсии, что резко ограничивает их возможности выбора стратегии экономического поведения [Елютина, Болотов 2017].

Большинством авторов старение населения рассматривается как вызов для экономики развитых стран. Выделяются следующие негативные факторы, обусловленные старением населения: рост пенсионных расходов, сокращение потребления, замедление роста ВВП, торможение инвестиций.

\section{ВЛИЯНИЕ СТАРЕНИЯ НАСЕЛЕНИЯ НА ПОЛИТИЧЕСКИЕ ПРОЦЕССЫ}

\section{Стареющие руководители}

Одним из очевидных последствий старения населения может стать повышение возраста правящей элиты, что чревато установлением геронтократии. Изучение этого феномена активно продолжалось в 1970-80-е годы, что было связано с очевидным старением руководства в странах социалистического лагеря.

Исследователи геронтократий были вынуждены опираться на данные психологов, поскольку без психологии разобраться в мотивах престарелых руководителей было бы невозможно. А. Макинтайр писал: «Существование геронтократии заставляет поставить вопрос: каковы последствия старения для политических лидеров? Чтобы ответить на этот вопрос, необходимо провести более общее изыскание: каковы психологические эффекты старения (а также сопутствующие биологические и социальные эффекты). Эти вопросы ведут нас в относительно молодую область знания - психологию старости» [McIntyre 1988]. В ход шла методология бихевиорализма - методологического подхода, разработанного

\footnotetext{
2 May B.A. (2012). Пенсия как личный выбор // Ведомости. 3 августа. URL: https://www.vedomosti.ru/opinion/articles/2012/08/03/pensiya_i_my (дата обращения: 11.09.2017).
} 
Г. Лассуэллом в середине XX века, который предполагает учитывать психологические особенности участников политического процесса. Сам Макинтайр, а также авторы сборника под его редакцией обращались к психологическим теориям Фрейда, Юнга и Эриксона. Такой подход позволял, в частности, описать поведение престарелого Мао Цзэдуна через призму личностного конфликта между «цельностью и отчаяньем», характерного для пожилого возраста по Эрику Эриксону. В России, считает Вишневский, постаревшие общества могут стать более консервативными и «геронтократическими», и предполагает, что ситуацию могут спасти «возрастные квоты при заполнении определенного рода вакансий» [Вишневский 2005].

\section{Политическое поведение пожилых}

Политическое поведение пожилых изначально исследовалось вместе с электоральным поведением других возрастных групп. В 1960 г. вышла фундаментальная работа Кэмпбелла, Конверса, Миллера и Стоукса «Американский избиратель» [Campbell et al. 1960], в которой была выдвинута концепция, по которой избиратели голосуют согласно давно установившейся партийной идентификации, зачастую унаследованной от предков. Разумеется, пожилые избиратели демонстрировали высокую лояльность партиям, за которые голосовали в молодые годы. Работа была написана на базе Мичиганской модели, разработанной в 1950-е годы в Мичиганском университете, согласно которой избирателем движет психологически обусловленное чувство привязанности к своей партии. Эта же модель была позднее использована Батлером и Стоуксом на британском материале [Butler, Stokes 1971].

Между тем политологи стали осознавать растущее политическое влияние пожилых избирателей, связывая это не только с ростом доли пожилых, но и с ростом активности организаций, представляющих их интересы [Weaver 1976]. Вставал вопрос о том, чем поведение пожилых избирателей отличается от остальных. Мичиганская модель была подвергнута критике в работе Фиорины, который объяснял устойчивую приверженность избирателей, в том числе пожилых, той или иной партии с позиций теории рационального выбора, отвергая тем самым представление о слепой лояльности партийному флагу [Fiorina 1981]. Мичиганскую модель критиковали Миллер и Шэнкс, утверждавшие, что электоральная активность пожилых ситуативна и связана с особенностями жизненного опыта когорт [Miller, Shanks 1996]. Они соглашались с тем, что пожилые склонны голосовать за партию, которую долгие годы считают своей, однако сам выбор не наследуется от предков, а зависит от политической ситуации, в которой он был изначально сделан. Так появляются «поколение Кеннеди», «поколение Рейгана» и др. Исследование было проведено с привлечением материалов по американским выборам с 1952 по 1992 г. Миллер и Шэнкс также доказали, что пожилые голосуют гораздо активнее, чем представители других возрастных групп, причем с 1972 по 1992 г. этот разрыв увеличивался. Джекобс также пришел к выводу, что пожилые голосуют активнее более молодых [Jacobs 1990].

Большинство исследователей пытались объяснить высокую активность пожилых, исходя из парадигмы рационального выбора, полагая, что старики активно голосуют из-за более высокой заинтересованности во влиянии на принятие политических решений 
(заинтересованность в повышении пособий, медицинских страховках и др.). Кроме того, Тимпон установил, что на активность избирателя влияет то, как долго он проживает на одном месте, так что пожилые избиратели, долго прожившие в своем избирательном округе, чаще ходят на выборы [Timpone 1998].

Долговременное исследование политического участия американцев, длившееся 17 лет, показало, что с возрастом люди все больше отказываются от наиболее активных форм политической борьбы [Jennings, Markus 1988]. Столь же предсказуемыми оказались результаты Мело и Стокемера, которые на материале Германии, Франции и Великобритании показали, что пожилые, в отличие от молодежи, активнее участвуют в выборах, но реже принимают участие в уличных демонстрациях и других формах активного политического действия [Melo, Stockemer 2014]. Другие исследователи также подтверждают вывод о том, что пожилые являются наиболее активными избирателями. Из последних работ, подтверждающих эту гипотезу, можно назвать статью Нигарда и Якобссона, написанную на материале Финляндии [Nygard, Jakobsson 2013].

Вместе с тем, хотя внешне пожилые ведут себя сходным образом во всем мире, у политологов нет уверенности в том, что они принимают решения иначе, чем представители иных возрастных групп, и что вообще возможно говорить о пожилых как об отдельной группе интересов. В частности, Гоеррес, обобщив данные по двадцати с лишним странам Европы, пришел к выводу, что единого образца политического поведения пожилых не существует. Ситуация меняется от страны к стране и от когорты к когорте [Goerres 2009].

Так или иначе, для исследователей было очевидно, что высокая активность пожилых избирателей вместе с ростом их доли в населении ведут к повышению их роли в политической жизни развитых стран.

\section{Ценности пожильх}

Важнейшей проблемой политической геронтологии можно считать вопрос о том, что сильнее влияет на политические пристрастия пожилых: возрастные особенности их психологии или принадлежность к когорте, пережившей свой уникальный исторический опыт. О важности когортного анализа для понимания изменений общественного мнения одним из первых заговорил Эван [Evan 1959].

Одним из наиболее устойчивых стереотипов является представление о консерватизме пожилых. Традиционно считается, что молодежь охотнее воспринимает перемены, в то время как старики сохраняют верность традициям. Таких взглядов придерживался, в частности, Зеллман, считавший, что консерватизм пожилых избирателей обусловлен их озабоченностью вопросами безопасности, порядка и здоровья [Zellman 1975]. Криттенден считал, что политическое поведение пожилых не может объясняться только политическим опытом, полученным в юности (Первая мировая война, Великая депрессия и др.). По его мнению, пожилому возрасту соответствуют политические пристрастия, которые можно охарактеризовать как консервативные [Crittenden 1962].

Иной точки зрения придерживается Глен, полагавший, что понятие «консерватизм» может трактоваться двояко: либо как приверженность старому, либо как враждебность 
либеральным идеям. Когортный анализ американских избирателей показал, что пожилые американцы с годами становились более либеральными, однако усваивали новые идеи медленнее, чем их более молодые соотечественники [Glenn 1974]. Несколько раньше Глен и Хефнер показали, что с возрастом американцы не склонны менять свои убеждения на более консервативные [Glenn, Hefner 1972]. Исследование Кэмбелла и Стрейта [Campbell, Strate 1981] также не показало дрейфа когорт в сторону консерватизма. Хардинг проблематизирует само понятие консервативных ценностей, демонстрируя, что даже среди консерваторов рейгановско-тетчеровской эпохи не было единства по поводу того, что считать консервативными ценностями [Harding 1999].

Важным аргументом в пользу устойчивости ценностей и политических взглядов на протяжении жизни стало долговременное исследование, начатое Т. Ньюкомом в 1930-е годы и завершенное его учениками Д. Алвином и Р. Коэном в 1991 г. [Alwin et al. 1991]. Наблюдение за бывшими студентками Беннингтонского колледжа показало, что в юности девушки легко меняли политические взгляды, подвергаясь влиянию либеральной профессуры, но в дальнейшем их убеждения стабилизировались, в особенности если их взгляды совпадали со взглядами их мужей.

Ряд исследователей считали, что даже если пожилым не присущ природный консерватизм, они могут осознать себя особой группой интересов и начать оказывать влияние на государственную политику. В середине 1960-х годов Роуз считал, что пожилые американцы, оказавшись под влиянием общих экономических проблем, будут быстро превращаться в отдельную группу интересов, отказавшись от прежних партийных и идеологических идентичностей [Rose 1965]. Несколько позже Рили уподоблял возрастную стратификацию классовому делению общества [Riley 1971]. Пратт подчеркивал, что общественные организации, представлявшие интересы пожилых, добились значительных успехов в лоббистской деятельности [Pratt 1974]. Однако ожидания возрастного конфликта оказались преждевременными. Дэй показала, что, хотя политические группы, лоббирующие интересы пожилых в Вашингтоне, усиливают свое влияние, сами пожилые вовсе не объединены стремлением принудить государство к развитию выгодных для них социальных программ [Day 1990]. В целом американские исследователи обычно склонны полагать, что у пожилых нет каких-то особых политических предпочтений, поскольку эта возрастная группа также разделена внутри себя, как и другие возрастные группы

Родбек показала, что лица старше 65 лет не являют собой единую группу интересов и не имеют согласия даже по вопросам социального обеспечения пожилых [Rhodebeck 1993]. Согласно Родбек, пожилые разделены по социальному положению и партийной принадлежности, как и остальное население, и это разделение играет более важную роль, чем принадлежность к возрастной группе. Аналогичную позицию занимает Дж. ХэмилЛакер, которая считает, что различия расы, пола, образовательного уровня и классовой принадлежности сильнее влияют на электоральное поведение, чем возрастная группа [Hamil-Luker 2001]. Недавнее исследование Исследовательского центра Пью, посвященное голосованию на президентских выборах в США, подтвердило, что идеологическое разделение внутри пожилых когорт значительнее, чем разрыв между когортами [Desilver 2014]. В то же время Эрк, работающий с данными по странам Европы, предполагает, что возрастные группы имеют тенденцию превращаться в группы интересов, однако 
межпоколенческий конфликт вряд ли станет столь же глубоким, как классовый [Erk 2015]. Лансиа и Руссо считают, что, несмотря на растущий политический вес, пожилые не стремятся перераспределять общественные ресурсы в свою пользу в ущерб интересам молодежи, поскольку старшее поколение осознает важность воспроизводства человеческого капитала [Lancia, Russo 2016].

Между тем Тилли и Эванс, изучая выборы в Великобритании, пришли к другим выводам [Tilley, Evans 2014]. По их данным, возраст является значимым предиктором электорального поведения, и с возрастом повышается вероятность голосования за консерваторов. При этом они подтверждают гипотезу о существовании политических поколений, указывая, что избиратели, чье взросление пришлось на 1930-е, 1950-е и 1980-е годы, имеют склонность голосовать за консерваторов.

В настоящее время существуют методологические предпосылки, позволяющие обнаружить отклонения в ценностях пожилых людей, способные повлиять на их политические позиции. Теория базовых индивидуальных ценностей Шварца [Schwartz 1992] предполагает, что политические симпатии индивида определяются его базовыми ценностями, такими как власть, традиция, безопасность, удовольствия, независимость и др. По мнению Шварца и его соавторов, возраст, пол, уровень образования и дохода оказывают минимальное воздействие на решения избирателей, в то время как базовые ценности играют решающую роль [Schwartz et al. 2010; 2015]. В то же время безопасность является у Шварца одной из ключевых ценностей, а стремление к избеганию риска, как отмечалось выше, часто наблюдается у пожилых.

В исследовании, предпринятом после выборов президента США 2008 г., было показано, что люди, для которых безопасность является ведущей ценностью, чаще голосовали за Маккейна, однако такая ценностная ориентация никак не коррелировала с преклонным возрастом. Напротив, оказалось, что пожилые чаще голосовали за Обаму, обещавшего социальные льготы [Dirilen-Gümüş et al. 2012]. Ариза-Монтес, ТирадоВаленсия и Висенте показали, что именно система ценностей влияет на то, будут ли пожилые участвовать в волонтерской деятельности [Ariza-Montes et al. 2017].

Между тем различные исследования подтверждают, что пожилые когорты в разных странах могут иметь особые ценности, связанные с их жизненным опытом и культурными особенностями страны. В частности, оказалось, что пожилые в целом остаются приверженцами семейных ценностей. Об этом не раз говорится в сборнике «Глобальное старение и вызовы для семьи» под редакцией Бенгстона и Ловенстейн [Bengston, Lowenstein 2003]. К таким же выводам пришел Писарев на российском материале [Писарев 2005], показавший, что российским пенсионерам важнее всего семья, здоровье и покой. Другие российские исследователи пришли к сходным результатам. По данным Хвалиной, среди главных ценностей российских пожилых оказались здоровье, семья, наличие друзей, материальная обеспеченность и активная деятельность [Хвалина 2009]. Щанина также подчеркивает, что основной ценностью для российских пожилых является семья: пенсионеры хотят чувствовать себя нужными, и лишь в семье они могут ощутить свою востребованность [Щанина 2015]. 
Вместе с тем Левинсон выделил несколько особенностей сознания российских пенсионеров, среди которых социальная и психологическая зависимость от государства, высокая восприимчивость к телевизионной пропаганде, позитивное восприятие реабилитации символов советского прошлого [Левинсон 2012]. Он также полагает, что идеология российских пожилых, т.е. людей, сформировавшихся в советский период, превратилась в общую идеологию российского общества, что объективно мешает стране идти по пути модернизации [Левинсон 2011]. Однако «советские ценности» также постепенно меняются. Ковалева на основе исследования, проведенного Самарским НИИ «Международный центр по проблемам пожилых», показала, что к началу XXI века ценности пожилых россиян существенно изменились по сравнению с концом 1970-х годов. В частности, на первый план выдвинулось «материальное благополучие», а ценность труда заметно снизилась [Ковалева 2001]. Все эти особенности и изменения напрямую связаны с жизненным опытом поколений. Сравнительное исследование ценностей возрастных когорт в США и Китае также показало, что ценности поколений напрямую связаны с пережитым историческим опытом [Egri, Ralston 2004].

В то же время открытым остается вопрос о влиянии психических и когнитивных особенностей пожилых людей на их мировоззрение. Естественные возрастные изменения в организме ведут к изменениям в мозговой деятельности, что может влиять на принятие политических решений. Еще в конце 1980-х годов крупный советский нейрофизиолог А.Б. Коган отмечал: «С возрастом стереотипы крепнут и их становится все труднее изменять. Отсюда известный консерватизм пожилых людей, у которых к тому же снижается подвижность основных нервных процессов. Переделка сложившихся стереотипов всегда представляет значительную трудность для нервной системы» [Коган 1988].

Герстейн одним из первых попытался создать модель поведения избирателей, учитывая ограниченность способности человеческого мозга к переработке информации [Herstein 1981]. Барон и Брек исследовали память и когнитивные способности пожилых в сравнении с молодыми и, в частности, установили, что у пожилых богаче словарный запас, а молодые лучше воспринимают цифры [Baron, Breck 1987]. Джонсон и Риггл показали, что молодые и пожилые избиратели по-разному обрабатывают информацию о кандидатах. Молодых больше интересуют пункты программы, в то время как пожилых больше интересуют личности кандидатов [Johnson, Riggle 1996]. Весьма интересное исследование было проведено в 1990 г. группой исследователей, которые в лабораторных условиях изучали механизмы принятия решений у менеджеров, принадлежавших к трем возрастным группам: молодым (28-35 лет), среднего возраста (45-55 лет) и пожилым (65-75 лет). Пожилые менеджеры принимали в целом меньше решений и больше опирались на опыт, чем на входящую информацию. Их решения были реже ориентированы на долгосрочную перспективу. В то же время пожилые реагировали на кризисные ситуации с тем же успехом, что и две другие группы [Streufert et al. 1990].

Ряд современных исследователей считают, что пожилым свойственна когнитивная ригидность и узость мышления [Jost et al. 2003].

Другие отмечают, что взгляды пожилых крайне стабильны, что означает их высокую сопротивляемость переменам [Alwin, Krosnick 1991]. 
Рэдлоск обратил внимание на то, что память играет важную роль в принятии электоральных решений, поскольку избиратель должен обрабатывать большие объемы информации, и именно пожилых избирателей память нередко подводит [Redlawsk 1996].

В целом подтверждается точка зрения Норвала Глена, согласно которой консерватизм пожилых носит скорее психологический, чем идеологический или ценностный характер [Glenn 1974]. Пожилые люди в разных странах имеют разные ценности, что связано с опытом когорт, формировавшихся и проживавших в разных исторических условиях.

Данный обзор не претендует на то, чтобы предложить оригинальное решение проблемы ценностей пожилых. Однако, как представляется, знакомство с приведенным материалом может облегчить задачу исследователям, занимающимся решением конкретных научных задач, от результатов которых зависит выработка политических подходов к проблемам пожилых людей.

\section{ЛИТЕРАТУРА}

Вишневский А.Г. (2005). Похвала старению // Отечественные записки. URL: http://www.strana-oz.ru/2005/3/pohvala-stareniyu (дата обращения: 11.05.2017).

Елютина М.Э., Болотов Г.И. (2017). Повседневная жизнь пожилой семьи: стратегия планирования и жесткой экономии ресурсов // Известия Саратовского университета. 17.1: $10-14$.

Ковалева Н.Г. (2001). Пожилые люди: социальное самочувствие // Социологические исследования. 7: 73-79.

Коган А.Б. (1988). Основы физиологии высшей нервной деятельности. М.: «Книга по Требованию». $368 \mathrm{c.}$

Кравчук П.Ф., Шкарина Ю.Ю. (2007). Особенности социальных взаимоотношений между пожилыми людьми и молодежью в современном российском обществе // Вопросы культурологии. 7: 39-42.

Краснова О. (2005). Порождение заблуждений: пожилые люди и старость // Отечественные записки. 3. URL: http://www.strana-oz.ru/2005/3/porozhdeniezabluzhdeniy-pozhilye-lyudi-i-starost (дата обращения: 11.05.2017).

Левинсон А.Г. (2011). Институциональные рамки старости // Вестник общественного мнения: данные, анализ, дискуссии. 109. 3: 52-81.

Левинсон А.Г. (2012). Пенсионеры как социальная группа и политическая сила // Демоскоп Weekly. 99-500. URL: http://demoscope.ru/weekly/2012/0499/tema010.php (дата обращения: 11.05.2017).

Писарев А.В. (2004). Образ пожилых в современной России // Социологические исследования. 4: 51-56.

Писарев А.В. (2005). Ценностные предпочтения пожилого населения и оценка их потенциала российским обществом. М.: Российская академия наук, Институт социально-политических исследований. 22 с. 
Рогозин Д.М. (2012). Либерализация старения, или труд, знания и здоровье в старшем возрасте // Социологический журнал. 4: 62-93.

Смирнова Т.В. (2008). Пожилые люди: стереотипный образ и социальная дистанция // Социологические исследования. 8: 49-55.

Смолькин А.А. (2007). Медицинский дискурс в конструировании образа старости // Журнал социологии и социальной антропологии. Х. 2(39): 134-141.

Смолькин А.А. (2010). Межпоколенческие конфликты в повседневной жизни // Социологические исследования. 11: 110-114.

Смолькин А.А. (2014). Трудовой потенциал пожилых людей // Социологические исследования. 5: 97-103.

Смолькин А.А. (2015). Практики повседневных межпоколенческих конфликтов глазами студентов провинциального вуза: этнографическое эссе // Антропологический форум. 25: 91-117.

Хвалина Н.В. (2009). Ценностные ориентации людей пожилого возраста и их представление о ценностных ориентациях значимых других // Известия Российского государственного педагогического университета им. А.И. Герцена: 408-411.

Щанина Е.В. (2015). Интеграция пожилых людей в современный социум // Известия высших учебных заведений, Поволжский регион. 1 (33): 150-153.

Alders P. (1999). Family ties in an aging world. Causes and consequences of fertility shifts. Rotterdam: Erasmus univ. Amsterdam: Thela-thesis. 186 p.

Alwin D.F., J.A. Krosnick (1991). Ageing, cohorts and the stability of sociopolitical orientations over the life span // American journal of sociology. 97: 169-195.

Alwin D.F., R.L. Cohen, T.M. Newcomb (1991). Political attitudes over the life span: The Bennington women after fifty years. Madison, Wis: University of Wisconsin press. $452 \mathrm{p}$.

Ariza-Montes A., P. Tirado-Valencia, F.R. Vicente (2017). Human values and volunteering: A study on elderly people // Intangible capital. 13, 2: 253-281.

Baars J., D. Dannefer, C. Phillipson, A. Walker (2006). Aging, globalization, and inequality: the new critical gerontology. Baywood Pub. 304 p.

Bakshi G.S., Z. Chen (1994). Baby boom, population aging, and capital markets // Journal of business. 67(2): 163-202.

Baron A., D.B.L. Breck (1987). Are older adults generally more conservative? some negative evidence from signal detection analyses of recognition memory and sensory performance // Experimental aging research. 13, 3: 163-165.

Bengston V.L., A. Lowenstein (eds) (2003). Global aging and challenges to families. New York: Aldine de Gruyter. 387 p.

Binstock R. H. (1974) Aging and the Future of American Politics // The annals of the american academy of political and social science. 415: 199-212.

Binstock R.H. (1972). Interest-group liberalism and the politics of aging // The Gerontologist 12: 265-280

Brewer M.B., V. Dull, L. Lui (1981). Perceptions of the elderly: stereotypes as prototypes // Journal of personality and social psychology. 41(4): 656-670.

Bromley D.B. (1966). Psychology of human aging. Baltimore, Maryland: Penguin. 448 p. 
Brown R.L., D.A. Rohlinger (2016). The effect of political generation on identity and social change: age cohort consequences // Journal of women \& aging. 28, 2: 96-111.

Butler D. D.E. Stokes (1971). Political change in Britain. London: Pelican.

Butler R.N (1969). Age-ism: another form of bigotry // The gerontologist. 9, 4, pt. 1: 243-246.

Campbell A. (1971). Politics through the life cycle // The gerontologist. 11: 112-117

Campbell A., P. Converse, W.E. Miller, D.E. Stokes (1960). The American voter. The University of Chicago press: Chicago, by John Wiley \& Sons, Inc. 576 p.

Campbell J.C., J. Strate (1981). Are old people conservative? // The gerontologist. 21 (6): 58059.

Casamatta G., L. Batté (2016). The political economy of population aging // Handbook of the economics of population aging. 1: 381-444.

CIA (2001). Long term global demographic trends: reshaping the geo-political landscape. July 2001.

Cohn J.M. (2016). Aging in comparative perspective: processes and policies, by Ian Gillespie Cook and Jamie Halsal // Journal of aging, longevity, law, and policy. 1: 131-136.

Cool D. (2012). Reconstructing the elderly: a critical analysis of pensions and population policies in an era of demographic ageing // Contemporary political theory. 11,1: 41-67.

Crittenden J.A. (1962). Aging and party affiliation // Public opinion quarterly. 26: 648-657.

Cumming E., W. Henry (1961). Growing old: the process of disengagement. New York: Basic Books. 310 p.

Cutler N.E. (1970). Generation, maturation, and party affiliation: a cohort analysis // Public opinion quarterly. 33: 583-588.

Cutler N.E. (1977). Demographic, social psychological, and political factors in the politics of aging: a foundation for research in "political gerontology" // American political science review. 71: 1011-1025.

Day C.L. (1990). What older Americans think: interest groups and aging policy. Princeton, NJ: Princeton University.

Desilver D. (2014). The politics of American generations: how age affects attitudes and voting behavior // Pew research center. URL: http://www.pewresearch.org/fact-tank/2014/07/09/thepolitics-of-american-generations-how-age-affects-attitudes-and-voting-behavior/ (дата обращения: 11.05.2017).

Dirilen-Gümüş Ö., S.E. Cross, A. Dönmez (2012). Who voted for whom? Comparing supporters of Obama and McCain on value types and personality traits // Journal of applied social psychology. 42: 2879-2900.

Drydakis N., P. MacDonald, V. Chiotis, L. Somers (2017). Age discrimination in the UK labour market. Does race moderate ageism? An experimental investigation // Applied economics letters: $1-4$.

Egri C.P., D.A. Ralston (2004). Generation cohorts and personal values: a comparison of China and the United States // Organization science. 15(2): 210-220.

Erikson E. (1982). The life cycle completed. New York, NY: Norton. 144 p.

Erikson E., Erikson J., Kivnick H.Q. (1986). Vital involvement in old age. New York, NY: Norton. 352 p. 
Erk J. (2015). Is age the new class? Economic crisis and demographics in European politics // Critical sociology: 1-3.

Evan W.M. (1959). Cohort analysis of survey data: a procedure for studying longterm opinion change // Public opinion quarterly. 23: 63-72.

Featherstone M., A. Wernick (1995). Images of ageing. London: Routledge. 331 p.

Fiorina M.P. (1981). Retrospective voting in American national elections. New Haven, CT: Yale University. 249p.

Glenn N. (1974). Aging and conservatism // Annals of the American Academy of political and social science. 415: 176-186.

Glenn N.D. (1969). Aging, disengagement, and opinionation // Public opinion quarterly. 33: 1733.

Glenn N.D., M. Grimes (1968). Aging, voting, and political interest // American sociological review. 33. 4: 563-575.

Glenn N.D., T. Hefner (1972). Further evidence on aging and party identification // Public opinion quarterly. 36: 31-47.

Goerres A. (2009). The political participation of older people in Europe. The greying of our democracies. London: Palgrave Macmillan. 234 p.

Gonzalez-Eiras M., D. Niepelt (2012a). Aging, government budgets, retirement, and growth // European economic review. Elsevier. 56 (1): 97-115.

Gonzalez-Eiras M., D. Niepelt (2012b). Economic and politico-economic equivalence // Working papers. 12.02. Swiss National Bank, Study Center Gerzensee: 1-34.

Grant J., S. Hoorens (2006). The new pronatalism? The policy consequences of population ageing // Public policy research. 13 (1): 13-25.

Hagestad G., P. Uhlenberg (2006). Should we be concerned about age segregation? Some theoretical and empirical explorations // Research on aging. 28(6): 638-653.

Hamil-Luker J. (2001). The prospects of age war: inequality between (and within) age groups // Social science research. 30: 386-400.

Harding F. (1999). "Family values" and conservative government policy: 1979-97 // Changing Family Values / G. Jagger, C. Wright, eds. London: Routledge: 119-135.

Harris K., S. Krygsman, J. Waschenko, D.L. Rudman (2017). Ageism and the older worker: a scoping review // The gerontologist. URL: https://www.ncbi.nlm.nih.gov/pubmed/28082278 (дата обращения: 11.05.2017).

Havighurst R.J., R.E. Albrecht (1953). Older people. New York: Longmans \& Green. 415 p.

Heller P.S. (2003). Who will pay? Coping with aging societies, climate change, and other longterm fiscal challenges. Washington, DC: International Monetary Fund. 315 p.

Herstein J.A. (1981). Keeping the voter's limits in mind: a cognitive process analysis of decision making in voting / /Journal of personality and social psychology. 40: 843-861.

Hummert M.L. (1990). Multiple stereotypes of elderly and young adults: a comparison of structure and evaluations // Psychology and aging. 5(2): 182-193.

Hummert M.L., T.A. Garstka, J.L. Shaner (1995). Judgments about stereotypes of the elderly attitudes, age associations, and typicality ratings of young, middle-aged, and elderly adults // Research on aging. 17: 168-182. 
Hummert M.L., T.A. Garstka, J.L. Shaner (2004). Stereotypes of the elderly held by young, middle-aged, and elderly adults // The international journal of aging and human development. 58(4): 315-40.

International Monetary Fund (2000). Population aging and global capital flows in a parallel universe. Research dep., Washington.

International Monetary Fund (2002) The Aging of the population and the size of the welfare state. Western hemisphere dep., Washington.

International Monetary Fund (2005). Global aging and fiscal policy with international labor mobility: a political economy perspective. Research dep., Washington.

International Monetary Fund (2008). Global aging and declining world interest rates: macroeconomic insurance through pension reform in Cyprus. IMF inst. a. Europ. Dep. Washington.

Jackson J.J. (1974). NCBA, black aged and politics // Annals of the American academy of political and social science. 415: 138-159.

Jackson R., N. Howe (2008). The graying of the great powers. Demography and geopolitics in the 21st century. Washington, DC: Center for Strategic International Studies (CSIS). 224 p.

Jacobs B. (1990). Aging and politics // Handbook of Aging and the Social Sciences, 3rd ed. / R.H. Binstock, L.K. George, eds. San-Diego: Academic press. 349-361.

Jennings M.K., G.B. Markus (1988). Political involvement in the later years: a longitudinal study // American journal of political science. 32: 302-316.

Johnson M.M.S., E.D.B. Riggle (1996). Age difference in political decision making: Strategies for evaluating political candidates // Political Behavior. 1. 18, 1: 99-118.

Jost J.T., J. Glaser, A.W. Kruglanski, F.J. Sulloway (2003). Political conservatism as motivated social cognition // Psychological bulletin. 129: 339-375.

Kasnauskiene G., K. Michnevic (2015). The effects of demographic trends on economic growth in the European Union // European scientific journal. Special edition. 2: 70-85.

King S.P., F.B. Bryant (2017). The Workplace intergenerational climate scale (WICS): a selfreport instrument measuring ageism in the workplace // Journal of Organizational behavior. 38, 1: 124-151.

Komp K. (2011). The political economy of the third age // Gerontology in the era of the third age / D. Carr, K. Komp, eds. New York: Springer: 51-66.

Komp K. (2013). political gerontology: population ageing and the state of the state // Old age in Europe / K. Komp, M. Aarsten, eds. Amsterdam: Springer: 59-77.

Komp K., M. Aarsten, eds. (2013). Old age in Europe: a textbook of gerontology. Dordrecht; New York: Springer. 148 p.

Komp K., P. Marier, eds. (2015). Population ageing from a lifecourse perspective: Critical and international approaches. Bristol: Policy press. 304 p.

Komp K., T. Van Tilburg (2010). Ageing societies and the welfare state: where the intergenerational contract is not breached // International journal of ageing and later Life. 5(1): 711.

Komp K., T. Van Tilburg, M.B. Van Groenou (2010). Paid work between age 60 and 70 years in Europe: a matter of socio-economic status? // International journal of ageing and later life. 5(1): 45-75. 
Kuhlen R.G. (1956). Changing personal adjustment during adult years // Psychological aspects of aging / J. Anderson, ed. New York: American Psychological Association: 21-35.

Lancia F., A. Russo (2016). Public education and pensions in democracy: a political economy theory // Journal of the European economic association. 14, 5: 1038-1073.

Lisenkova K., M. Mérette, R. Wright (2012). The impact of population ageing on the labour market: evidence from overlapping generations computable general equilibrium (OLG-CGE) model of Scotland // Discussion paper in economic, strathclyde: 12-13.

Magnus G. (2009). The age of aging. How demographics are changing the global economy and our world. Singapore: John Wiley \& Sons (Asia). 321 p.

Marques S., C.M. Vauclair, H.J. Swift, C. Bratt (2017). Social psychology and gerontology: integrating theory to explain and intervene in age discrimination towards older people in Europe // Cross-disciplinary perspectives in social gerontology. Springer: 45-66.

McInish T.H., S.N. Ramaswami, R.K. Srivastava (1993). Do more risk-averse investors have lower net worth and income? // The financial review. 28 (1): 91-106.

McIntyre A. (1988). Aging and political leadership. Oxford university press. $321 \mathrm{p}$.

Melo D.F., D. Stockemer (2014). Age and political participation in Germany, France and the UK: a comparative analysis // Comparative european politics. 12, 1: 33-53.

Michnevic K. (2016). The effects of ageing on household consumption in Central and Eastern Europe // Economy \& business journal. 10, 1: 273-287.

Miller D.W., T.S. Leyell, J. Mazachek (2004). Stereotypes of the elderly in U.S. Television commercials from the 1950s to the 1990s. // The international journal of aging and human development. 58(4): 315-40.

Miller W.E., J.M. Shanks (1996). The new American voter. Cambridge MA: Harvard university press. $668 \mathrm{p}$.

Mincer J., ed. (1974). Age and experience profiles of earnings. New York: Columbia University press: $64-82$.

Morin R.A., A.F. Suarez (1983). Risk aversion revisited // The journal of finance. 38(4): 12011216.

Nelson T.D. (2004). Ageism: stereotyping and prejudice against older persons. Cambridge, London: The MIT press. 388 p.

Nelson T.D. (2005). Ageism: prejudice against our feared future self //Journal of social issues. 61: 207-221.

Nelson T.D. (2016). The age of ageism // Journal of social issues. 72, 1: 191-198.

Neugarten, B.L. (1974). Age groups in American society and the rise of the young-old // Annals of the American Academy of political and social sciences. 415: 187-198.

Novikova K. (2016). "Mohair berets": Media representations of elderly right-wing women and aestheticization of age in Poland // Gender and far right politics in Europe. London: Palgrave Macmillan: 207-219.

Nygard M., G. Jakobsson (2013). Senior citizens and political participation: evidence from a Finnish regional study // Ageing and society. 33(1): 159-180.

Palmore E.B. (1999). Ageism: negative and positive. NY: Springer. 280 p. 
Palmore E.B. (2004). Research note: ageism in Canada and the United States // Journal of crosscultural gerontology. 19, 1: 41-46.

Palmore E.B. (2005). Three Decades of Research on Ageism // Generations. 29(3): 87-90.

Palmore E.B. (2009). Reducing ageism // Journal of aging, humanities and the arts. 3(2), 144146.

Palmore E.B. (2011). Older can be bolder. New York, NY: CreateSpace and Kindle. 176 p.

Powell J.L. (2006). Social theory and aging. Oxford: Rowman \& Littlefield. 157 p.

Pratt H.J. (1974). Old age associations in national politics // Annals of the American academy of political and social science. 415: 106-119.

Redlawsk D.P. (1996). The role of memory in voter decision making a process tracing study of a presidential election campaign. Rutgers University Department of Political Science New Brunswick: 1-30.

Report of the Royal Commission on Population (1949). Published by HMSO, London.

Rhodebeck L.A. (1993). The politics of greed? Political preferences among the elderly // Journal of politics. 55: 342-364

Riley M.W. (1971). Social gerontology and the age stratification of society // The gerontologist. 11. I: 79-87.

Rose A.M. (1965). Older people and their social world. Philadelphia: F.A. Davis. 420 p.

Samanta T. (2017). Bridging the gap: theory and research in social gerontology // Cross-cultural and cross-disciplinary perspectives in social gerontology. Springer: 3-22.

Sanderson W.C., S. Scherbov (2007). A near electoral majority of pensioners: prospects and policies // Population and development review. 33 (3): 543-554.

Sanderson W.C., S. Scherbov (2016a). New approaches to the conceptualization and measurement of age and aging // Journal of aging and health. 28(7): 1159-1177.

Sanderson W.C., S. Scherbov (2016b). A new perspective on patterns of aging in Europe by education and gender // Journal of population ageing. 9 (3): 207-225.

Schwartz S.H. (1992). Universals in the content and structure of values: theoretical advances and empirical tests in 20 countries // Advances in experimental social psychology. 25 / M. Zanna, ed. New York: Academic press: 1-66.

Schwartz S.H., Caprara G.V., Vecchione M., etc. (2015). Personal values and political activism: A cross-national study // British journal of psychology. 106. 1: 84-106.

Schwartz S.H., G.V. Caprara, M. Vecchione (2010). Basic personal values, core political values, and voting: a longitudianal analysis // Political psychology. 31, 3: 421-452.

Streufert S., R. Pogash, M. Piasecki, G.M. Post (1990). Age and management team performance // Psychology and aging. 5: 551-559.

Tilley J., G. Evans (2014). Ageing and generational effects on vote choice: combining crosssectional and panel data to estimate APC effects // Electoral studies. 33: 19-27.

Timpone R.J. (1998). Structure, behavior, and voter turnout in the United States // The American political science review. 92, 1:145-158.

Vero D., B. Giardino (2017). Measuring urban ageing. Città Giardino Torino // Architectural research addressing societal challenges. Leiden: CRC Press/Balkema: 285-291. 
Weaver J.L. (1976). The elderly as a political community: the case of national health policy // Western political quarterly. 29(4): 610-649.

World Bank Report. (1994). Averting the old age crisis \#13584. New York: Oxford university press.

World Health Organization (WHO) (2002). Active ageing: A policy framework.

Zellman G.L. (1975). Antidemocratic beliefs: A survey and some explanations // Journal of social issues. 31 : 31-53. 


\title{
THE VALUES OF THE ELDERLY AND THE POLITICAL CONSEQUENCES OF THE GLOBAL AGING OF THE POPULATION
}

\author{
KIRILL NOVIKOV, DARIA BYKANOVA
}

\begin{abstract}
The review is devoted to several problems in political and social gerontology, as well as to economic problems caused by global aging of the population. The text contains an analysis of the approaches of different authors to the definition of old age and its psychological, behavioral and social aspects. The problems of active aging, the social construction of stereotypes regarding the elderly and ageism are also considered. Two main approaches to studying the economic consequences of population aging are described: the first analyzes macro-level trends caused by shifts in the ratio of the working and retired population, while the second focuses on the economic behavior of the elderly, including their behavior on the labor, financial and consumer markets. The participation of international organizations in the study of economic issues related to world demographic changes is also described. The review focuses primarily on research devoted to the political consequences of the growing share of the elderly population in modern society, especially in developed democracies. Also considered are approaches to describing the political activity of the elderly, including participation in elections, in protest actions, etc. Considerable attention is paid to the problem of the values of the elderly, especially their alleged conservatism. Some authors argue that the values of the elderly are associated with age-related changes of mind and body and therefore are age-related. Meanwhile, most contemporary researchers believe that values are developed in the process of socialization of the "political generations" and change little with ageing. The question is also asked whether the elderly are transforming into a separate group having its own interests and able to impose its special agenda on society. Finally, the review presents the results of studies on the cognitive abilities of the elderly influencing their ability to make political and other decisions.
\end{abstract}

Key words: population aging, politics, conservatism, values, ageism.

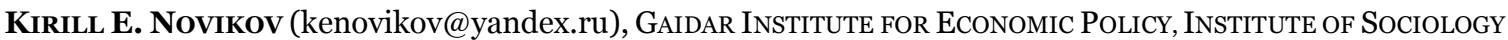
RAS, RUSSIA.

Daria A. Bykanova (bykanova-da@ranepa.ru), The Russian Presidential ACAdEMy of National Economy AND Public Administration (The Presidential ACAdEMy, RANEPA), Russia.

DATE RECEIVED: MAY 2017.

\section{REFERENCES}

Alders P. (1999). Family ties in an aging world. Causes and consequences of fertility shifts. Rotterdam: Erasmus univ. Amsterdam: Thela-thesis. 186 p.

Alwin D.F., J.A. Krosnick (1991). Ageing, cohorts and the stability of sociopolitical orientations over the life span // American journal of sociology. 97: 169-195.

Alwin D.F., R.L. Cohen, T.M. Newcomb (1991). Political attitudes over the life span: The Bennington women after fifty years. Madison, Wis: University of Wisconsin press. 452 p.

Ariza-Montes A., P. Tirado-Valencia, F.R. Vicente (2017). Human values and volunteering: A study on elderly people // Intangible capital. 13,2: 253-281.

Baars J., D. Dannefer, C. Phillipson, A. Walker (2006). Aging, globalization, and inequality: the new critical gerontology. Baywood Pub. 304p. 
Bakshi G.S., Z. Chen (1994). Baby boom, population aging, and capital markets // Journal of business. 67(2): 163-202.

Baron A., D.B.L. Breck (1987). Are older adults generally more conservative? some negative evidence from signal detection analyses of recognition memory and sensory performance // Experimental aging research. 13, 3: 163-165.

Bengston V.L., A. Lowenstein, eds. (2003). Global aging and challenges to families. New York: Aldine de Gruyter. 387 p.

Binstock R. H. (1974) Aging and the Future of American Politics // The annals of the american academy of political and social science. 415: 199-212.

Binstock R.H. (1972). Interest-group liberalism and the politics of aging // The Gerontologist 12: 265-280

Brewer M.B., V. Dull, L. Lui (1981). Perceptions of the elderly: stereotypes as prototypes // Journal of personality and social psychology. 41(4): 656-670.

Bromley D.B. (1966). Psychology of human aging. Baltimore, Maryland: Penguin. 448 p.

Brown R.L., D.A. Rohlinger (2016). The effect of political generation on identity and social change: age cohort consequences // Journal of women \& aging. 28, 2: 96-111.

Butler D. D.E. Stokes (1971). Political change in Britain. London: Pelican.

Butler R.N (1969). Age-ism: another form of bigotry // The gerontologist. 9, 4, pt. 1: 243-246.

Campbell A. (1971). Politics through the life cycle // The gerontologist. 11: 112-117

Campbell A., P. Converse, W.E. Miller, D.E. Stokes (1960). The American voter. The University of Chicago press: Chicago, by John Wiley \& Sons, Inc. 576 p.

Campbell J.C., J. Strate (1981). Are old people conservative? // The gerontologist. 21 (6): 58059.

Casamatta G., L. Batté (2016). The political economy of population aging // Handbook of the economics of population aging. 1: 381-444.

CIA (2001). Long term global demographic trends: reshaping the geo-political landscape. July 2001.

Cohn J.M. (2016). Aging in comparative perspective: processes and policies, by Ian Gillespie Cook and Jamie Halsal // Journal of aging, longevity, law, and policy. 1: 131-136.

Cool D. (2012). Reconstructing the elderly: a critical analysis of pensions and population policies in an era of demographic ageing // Contemporary political theory. 11,1: 41-67.

Crittenden J.A. (1962). Aging and party affiliation // Public opinion quarterly. 26: 648-657.

Cumming E., W. Henry (1961). Growing old: the process of disengagement. New York: Basic Books. 310 p.

Cutler N.E. (1970). Generation, maturation, and party affiliation: a cohort analysis // Public opinion quarterly. 33: 583-588.

Cutler N.E. (1977). Demographic, social psychological, and political factors in the politics of aging: a foundation for research in "political gerontology" // American political science review. 71: 1011-1025.

Day C.L. (1990). What older americans think: interest groups and aging policy. Princeton, NJ: Princeton University. 
Desilver D. (2014). The politics of American generations: how age affects attitudes and voting behavior // Pew research center. URL: http://www.pewresearch.org/fact-tank/2014/07/09/thepolitics-of-american-generations-how-age-affects-attitudes-and-voting-behavior/ (accessed: 11.05.2017).

Dirilen-Gümüş Ö., S.E. Cross, A. Dönmez (2012). Who voted for whom? Comparing supporters of Obama and McCain on value types and personality traits // Journal of applied social psychology. 42: 2879-2900.

Drydakis N., P. MacDonald, V. Chiotis, L. Somers (2017). Age discrimination in the UK labour market. Does race moderate ageism? An experimental investigation // Applied economics letters: $1-4$.

Egri C.P., D.A. Ralston (2004). Generation cohorts and personal values: a comparison of China and the United States // Organization science. 15(2): 210-220.

Elyutina M.E., Bolotov G.I. (2017). Povsednevnaya zhizn' pozhiloy sem'i: strategiya planirovaniya i zhestkoy ekonomii resursov [The daily life of an elderly family: a strategy for planning and austerity of resources] // Izvestiya Saratovskogo universiteta [Saratov University news]. 1.17: 1: 10-14.

Erikson E. (1982). The life cycle completed. New York, NY: Norton. 144 p.

Erikson E., Erikson J., Kivnick H.Q. (1986). Vital involvement in old age. New York, NY: Norton. 352 p.

Erk J. (2015). Is age the new class? Economic crisis and demographics in European politics // Critical sociology: 1-3.

Evan W.M. (1959). Cohort analysis of survey data: a procedure for studying longterm opinion change // Public opinion quarterly. 23: 63-72.

Featherstone M., A. Wernick (1995). Images of ageing. London: Routledge. 331 p.

Fiorina M.P. (1981). Retrospective voting in American national elections. New Haven, CT: Yale University. 249p.

Glenn N. (1974). Aging and conservatism // Annals of the American Academy of political and social science. 415: 176-186.

Glenn N.D. (1969). Aging, disengagement, and opinionation // Public opinion quarterly. 33: 1733.

Glenn N.D., M. Grimes (1968). Aging, voting, and political interest // American sociological review. 33. 4: 563-575.

Glenn N.D., T. Hefner (1972). Further evidence on aging and party identification // Public opinion quarterly. 36: 31-47.

Goerres A. (2009). The political participation of older people in Europe. The greying of our democracies. London: Palgrave Macmillan. 234 p.

Gonzalez-Eiras M., D. Niepelt (2012a). Aging, government budgets, retirement, and growth // European economic review. Elsevier. 56 (1): 97-115.

Gonzalez-Eiras M., D. Niepelt (2012b). Economic and politico-economic equivalence // Working papers. 12.02. Swiss National Bank, Study Center Gerzensee: 1-34.

Grant J., S. Hoorens (2006). The new pronatalism? The policy consequences of population ageing // Public policy research. 13 (1): 13-25. 
Hagestad G., P. Uhlenberg (2006). Should we be concerned about age segregation? Some theoretical and empirical explorations // Research on aging. 28(6): 638-653.

Hamil-Luker J. (2001). The prospects of age war: inequality between (and within) age groups // Social science research. 30: 386-400.

Harding F. (1999). "Family values" and conservative government policy: 1979-97 // Changing Family Values / G. Jagger, C. Wright, eds. London: Routledge: 119-135.

Harris K., S. Krygsman, J. Waschenko, D.L. Rudman (2017). Ageism and the older worker: a scoping review // The gerontologist. URL: https://www.ncbi.nlm.nih.gov/pubmed/28082278 (accessed: 11.05.2017).

Havighurst R.J., R.E. Albrecht (1953). Older people. New York: Longmans \& Green. 415 p.

Heller P.S. (2003). Who will pay? Coping with aging societies, climate change, and other longterm fiscal challenges. Washington, DC: International Monetary Fund. 315 p.

Herstein J.A. (1981). Keeping the voter's limits in mind: a cognitive process analysis of decision making in voting // Journal of personality and social psychology. 40: 843-861.

Hummert M.L. (1990). Multiple stereotypes of elderly and young adults: a comparison of structure and evaluations // Psychology and aging. 5(2): 182-193.

Hummert M.L., T.A. Garstka, J.L. Shaner (1995). Judgments about stereotypes of the elderly attitudes, age associations, and typicality ratings of young, middle-aged, and elderly adults // Research on aging. 17: 168-182.

Hummert M.L., T.A. Garstka, J.L. Shaner (2004). Stereotypes of the elderly held by young, middle-aged, and elderly adults // The international journal of aging and human development. 58(4): 315-40.

International Monetary Fund (2000). Population aging and global capital flows in a parallel universe. Research dep., Washington.

International Monetary Fund (2002) The Aging of the population and the size of the welfare state. Western hemisphere dep., Washington.

International Monetary Fund (2005). Global aging and fiscal policy with international labor mobility: a political economy perspective. Research dep., Washington.

International Monetary Fund (2008). Global aging and declining world interest rates: macroeconomic insurance through pension reform in Cyprus. IMF inst. a. Europ. Dep. Washington.

Jackson J.J. (1974). NCBA, black aged and politics // Annals of the American academy of political and social science. 415: 138-159.

Jackson R., N. Howe (2008). The graying of the great powers. Demography and geopolitics in the 21st century. Washington, DC: Center for Strategic International Studies (CSIS). 224 p.

Jacobs B. (1990). Aging and politics // Handbook of Aging and the Social Sciences, 3rd ed. / R.H. Binstock, L.K. George, eds. San-Diego: Academic press. 349-361.

Jennings M.K., G.B. Markus (1988). Political involvement in the later years: a longitudinal study // American journal of political science. 32: 302-316.

Johnson M.M.S., E.D.B. Riggle (1996). Age difference in political decision making: Strategies for evaluating political candidates // Political Behavior. 1. 18, 1: 99-118.

Jost J.T., J. Glaser, A.W. Kruglanski, F.J. Sulloway (2003). Political conservatism as motivated social cognition // Psychological bulletin. 129: 339-375. 
Kasnauskiene G., K. Michnevic (2015). The effects of demographic trends on economic growth in the European Union // European scientific journal. Special edition. 2: 70-85.

Khvalina N.V. (2009). Tsennostnye orientatsii lyudey pozhilogo vozrasta i ikh predstavlenie o tsennostnykh orientatsiyakh znachimykh drugikh [Value orientations of elderly people and their perception of value orientations of the significant other] // Izvestiya Rossiyskogo gosudarstvennogo pedagogicheskogo universiteta im. A.I. Gertsena [Newsletters of the Herzen State pedagogical university of Russia]: 408-411.

King S.P., F.B. Bryant (2017). The Workplace intergenerational climate scale (WICS): a selfreport instrument measuring ageism in the workplace // Journal of Organizational behavior. 38, 1: 124-151.

Kogan A.B. (1988). Osnovy fiziologii vysshey nervnoy deyatel'nosti [The fundamentals of physiology of higher nervous activity ]. Moscow: Kniga po trebovaniyu. 368 p.

Komp K. (2011). The political economy of the third age // Gerontology in the era of the third age / D. Carr, K. Komp, eds. New York: Springer: 51-66.

Komp K. (2013). political gerontology: population ageing and the state of the state // Old age in Europe / K. Komp, M. Aarsten, eds. Amsterdam: Springer: 59-77.

Komp K., M. Aarsten (eds.) (2013). Old age in Europe: a textbook of gerontology. Dordrecht; New York: Springer. 148 p.

Komp K., P. Marier, eds. (2015). Population ageing from a lifecourse perspective: Critical and international approaches. Bristol: Policy press. 304 p.

Komp K., T. Van Tilburg (2010). Ageing societies and the welfare state: where the intergenerational contract is not breached // International journal of ageing and later Life. 5(1): 711.

Komp K., T. Van Tilburg, M.B. Van Groenou (2010). Paid work between age 60 and 70 years in Europe: a matter of socio-economic status? // International journal of ageing and later life. 5(1): 45-75.

Kovaleva N.G. (2001). Pozhilye lyudi: sotsial'noe samochuvstvie [The elderly people: their social well-being] // Sociologicheskie issledovaniya universiteta [University's sociological research]. 7: 73-79.

Krasnova O. (2005). Porozhdenie zabluzhdeniy: pozhilye lyudi i starost' [Breeding delusions: old people and old age] // Otechestvenny'e zapiski [Domestic notes]. 3. URL: http://www.stranaoz.ru/2005/3/porozhdenie-zabluzhdeniy-pozhilye-lyudi-i-starost (accessed: 11.05.2017).

Kravchuk P.F., Shkarina U.U. (2007). Osobennosti sotsial'nykh vzaimootnosheniy mezhdu pozhilymi lyud'mi i molodezh'yu v sovremennom rossiyskom obshchestve [Describing the social relationships between the elderly and the youth in contemporary Russian society] // Voprosy kul'turologii [Questions of culturology]. 7: 39-42.

Kuhlen R.G. (1956). Changing personal adjustment during adult years // Psychological aspects of aging / J. Anderson, ed. New York: American Psychological Association: 21-35.

Lancia F., A. Russo (2016). Public education and pensions in democracy: a political economy theory // Journal of the European economic association. 14, 5: 1038-1073.

Levinson A.G. (2011). Institutsional'nye ramki starosti [The institutional framework of old age] // Vestnik obshchestvennogo mneniya: dannye, analiz, diskussii [Herald of public opinion: data, analysis, discussions]. 109. 3: 52-81. 
Levinson A.G. (2012). Pensionery kak sotsial'naya gruppa i politicheskaya sila [The Retired as a social group and political force ] // Demoskop Weekly [Demoskope Weekly]. 499-500. URL: http://demoscope.ru/weekly/2012/0499/tema010.php (accessed: 11.05.2017).

Lisenkova K., M. Mérette, R. Wright (2012). The impact of population ageing on the labour market: evidence from overlapping generations computable general equilibrium (OLG-CGE) model of Scotland // Discussion paper in economic, strathclyde: 12-13.

Magnus G. (2009). The age of aging. How demographics are changing the global economy and our world. Singapore: John Wiley \& Sons (Asia). 321 p.

Marques S., C.M. Vauclair, H.J. Swift, C. Bratt (2017). Social psychology and gerontology: integrating theory to explain and intervene in age discrimination towards older people in Europe // Cross-disciplinary perspectives in social gerontology. Springer: 45-66.

McInish T.H., S.N. Ramaswami, R.K. Srivastava (1993). Do more risk-averse investors have lower net worth and income? // The financial review. 28 (1): 91-106.

McIntyre A. (1988). Aging and political leadership. Oxford university press. 321 p.

Melo D.F., D. Stockemer (2014). Age and political participation in Germany, France and the UK: a comparative analysis // Comparative european politics. 12, 1: 33-53.

Michnevic K. (2016). The effects of ageing on household consumption in Central and Eastern Europe // Economy \& business journal. 10, 1: 273-287.

Miller D.W., T.S. Leyell, J. Mazachek (2004). Stereotypes of the elderly in U.S. Television commercials from the 1950s to the 1990s. // The international journal of aging and human development. 58(4): 315-40.

Miller W.E., J.M. Shanks (1996). The new American voter. Cambridge MA: Harvard university press. $668 \mathrm{p}$.

Mincer J., ed. (1974). Age and experience profiles of earnings. New York: Columbia University press: $64-82$.

Morin R.A., A.F. Suarez (1983). Risk aversion revisited // The journal of finance. 38(4): 12011216.

Nelson T.D. (2004). Ageism: stereotyping and prejudice against older persons. Cambridge, London: The MIT press. 388 p.

Nelson T.D. (2005). Ageism: prejudice against our feared future self //Journal of social issues. 61: 207-221.

Nelson T.D. (2016). The age of ageism // Journal of social issues. 72, 1: 191-198.

Neugarten, B.L. (1974). Age groups in American society and the rise of the young-old // Annals of the American Academy of political and social sciences. 415: 187-198.

Novikova K. (2016). "Mohair berets": Media representations of elderly right-wing women and aestheticization of age in Poland // Gender and far right politics in Europe. London: Palgrave Macmillan: 207-219.

Nygard M., G. Jakobsson (2013). Senior citizens and political participation: evidence from a Finnish regional study // Ageing and society. 33(1): 159-180.

Palmore E.B. (1999). Ageism: negative and positive. NY: Springer. 280 p.

Palmore E.B. (2004). Research note: ageism in Canada and the United States // Journal of crosscultural gerontology. 19, 1: 41-46. 
Palmore E.B. (2005). Three Decades of Research on Ageism // Generations. 29(3): 87-90.

Palmore E.B. (2009). Reducing ageism // Journal of aging, humanities and the arts. 3(2), 144146.

Palmore E.B. (2011). Older can be bolder. New York, NY: CreateSpace and Kindle. 176 p.

Pisarev A.V (2005). Tsennostnye predpochteniya pozhilogo naseleniya i otsenka ikh potentsiala rossiyskim obshchestvom [The Value-based preferences of the elderly population and assessment of their potential by Russian society]. Moscow: Rosciyskaya akademiya nauk, Institut sotsial'no-politicheskikh issledovaniy. $22 \mathrm{p}$.

Pisarev A.V. (2004). Obraz pozhilykh v sovremennoy Rossii [The image of the elderly in modern Russia] // Sotsiologicheskie issledovaniya [Sociological research]. 4: 51-56.

Powell J.L. (2006). Social theory and aging. Oxford: Rowman \& Littlefield. 157 p.

Pratt H.J. (1974). Old age associations in national politics // Annals of the American academy of political and social science. 415: 106-119.

Redlawsk D.P. (1996). The role of memory in voter decision making a process tracing study of a presidential election campaign. Rutgers University Department of Political Science New Brunswick: 1-30.

Report of the Royal Commission on Population (1949). Published by HMSO, London.

Rhodebeck L.A. (1993). The politics of greed? Political preferences among the elderly // Journal of politics. 55: 342-364

Riley M.W. (1971). Social gerontology and the age stratification of society // The gerontologist. 11. I: 79-87.

Rogozin D.M. (2012). Liberalizatsiya stareniya, ili trud, znaniya i zdorov'e v starshem vozraste [Liberalization of aging, or labor, knowledge and health in older age] // Sotsiologicheskiy zhurnal [Sociological journal]. 4: 62-93.

Rose A.M. (1965). Older people and their social world. Philadelphia: F.A. Davis. 420 p.

Samanta T. (2017). Bridging the gap: theory and research in social gerontology // Cross-cultural and cross-disciplinary perspectives in social gerontology. Springer: 3-22.

Sanderson W.C., S. Scherbov (2007). A near electoral majority of pensioners: prospects and policies // Population and development review. 33 (3): 543-554.

Sanderson W.C., S. Scherbov (2016a). New approaches to the conceptualization and measurement of age and aging // Journal of aging and health. 28(7): 1159-1177.

Sanderson W.C., S. Scherbov (2016b). A new perspective on patterns of aging in Europe by education and gender // Journal of population ageing. 9 (3): 207-225.

Schwartz S.H. (1992). Universals in the content and structure of values: theoretical advances and empirical tests in 20 countries // Advances in experimental social psychology. 25 / M. Zanna, ed. New York: Academic press: 1-66.

Schwartz S.H., Caprara G.V., Vecchione M., etc. (2015). Personal values and political activism: A cross-national study // British journal of psychology. 106. 1: 84-106.

Schwartz S.H., G.V. Caprara, M. Vecchione (2010). Basic personal values, core political values, and voting: a longitudianal analysis // Political psychology. 31, 3: 421-452.

Shhanina E.V. (2015). Integratsiya pozhilykh lyudey v sovremennyy sotsium [Integration of elderly people into modern society] // Izvestiya vysshikh uchebnykh zavedeniy, Povolzhskiy 
region [Newsletters of the higher educational institutes, Povolzhskiy region]. 1 (33): 150153.

Smirnova T.V. (2008 Pozhilye lyudi: stereotipnyy obraz i sotsial'naya distantsiya [The Elderly: stereotyped image and social distance] // Sotsiologicheskie issledovaniya [Sociological research]. 8: 49-55.

Smolkin A.A (2010). Mezhpokolencheskie konflikty v povsednevnoy zhizni [Intergenerational conflicts in everyday life] // Sotsiologicheskie issledovaniya [Sociological research]. 11: 110114.

Smolkin A.A (2014). Trudovoy potentsial pozhilykh lyudey [The labor potential of the elderly] // Sotsiologicheskie issledovaniya [Sociological research].5: 97-103.

Smolkin A.A. (2007). Meditsinskiy diskurs v konstruirovanii obraza starosti [Medical discourse in constructing of the image of old age] // Zhurnal sotsiologii i sotsial'noy antropologii [Journal of sociology and social anthropology]. X. 2(39): 134-141.

Smolkin A.A. (2015). Praktiki povsednevnykh mezhpokolencheskikh konfliktov glazami studentov provintsial'nogo vuza: etnograficheskoe esse [Practices of everyday intergenerational conflicts through the eyes of students from a provincial university: an ethnographic essay] // Antropologicheskiy forum [Anthropological forum]. 25: 91-117.

Streufert S., R. Pogash, M. Piasecki, G.M. Post (1990). Age and management team performance // Psychology and aging. 5: 551-559.

Tilley J., G. Evans (2014). Ageing and generational effects on vote choice: combining crosssectional and panel data to estimate APC effects // Electoral studies. 33: 19-27.

Timpone R.J. (1998). Structure, behavior, and voter turnout in the United States // The American political science review. 92, 1:145-158.

Vero D., B. Giardino (2017). Measuring urban ageing. Città Giardino Torino // Architectural research addressing societal challenges. Leiden: CRC Press/Balkema: 285-291.

Vishnevsky A.G. (2005). Pokhvala stareniyu [Praise for aging] // Otechestvennye zapiski [Annals of the Fatherland]. URL: http://www.strana-oz.ru/2005/3/pohvala-stareniyu (accessed: 11.05.2017).

Weaver J.L. (1976). The elderly as a political community: the case of national health policy // Western political quarterly. 29(4): 610-649.

World Bank Report. (1994). Averting the old age crisis \#13584. New York: Oxford university press.

World Health Organization (WHO) (2002). Active ageing: A policy framework.

Zellman G.L. (1975). Antidemocratic beliefs: A survey and some explanations // Journal of social issues. 31 : 31-53. 